\title{
A Correlative Study on Epistemic Modal Use and Tolerance of Ambiguity: Based on Functionalist Theories in Second Language Acquisition
}

\author{
Lai Peng \\ School of Foreign Languages, Sun Yat-sen University, Guangzhou, China
}

Email address:

flslp@mail.sysu.edu.cn

To cite this article:

Lai Peng. A Correlative Study on Epistemic Modal Use and Tolerance of Ambiguity: Based on Functionalist Theories in Second Language Acquisition. International Journal of Language and Linguistics. Vol. 9, No. 4, 2021, pp. 169-179. doi: 10.11648/j.ij11.20210904.15

Received: May 24, 2021; Accepted: June 7, 2021; Published: July 2, 2021

\begin{abstract}
Given the importance of epistemic modal use in academic writing, this study aims to investigate how well Chinese $\mathrm{PhD}$ students use English epistemic modals and whether their achievement in using English epistemic modals is correlated with their degree of Tolerance of Ambiguity (TOA) as a learning style. Fill-in-the-blank exercises were designed to test the participants' use of epistemic modal verbs in English. Based on theories about matching, embedding and form-function mapping in second language learning, this study analyzed the errors that participants made when they chose modal forms in English to express epistemic functions/meanings conveyed by Chinese modal verb “会” (hui) in different syntactic contexts. A questionnaire survey was conducted to measure the participants' degree of TOA and IBM SPSS 26.0 was used for statistical calculation of the correlation coefficient between the participants' scores of TOA and their scores in using epistemic modal verbs. It was found that the degree of TOA is significantly correlated with epistemic modal use, i.e., the less tolerant of ambiguity a participant was, the less successfully he/she did in using epistemic modal verbs. The results of this study carry implications for language teaching and indicate the necessity of enhancing acquisition of epistemic modality and raising students' tolerance of ambiguity.
\end{abstract}

Keywords: Tolerance of Ambiguity, Epistemic Modality, Correlation, Form-function Mapping

\section{Introduction}

\subsection{Epistemic Modality}

According to Coates (1983), there is the root-epistemic distinction in terms of modality, i.e., modality can be divided into two types: root modality and epistemic modality [1]. Root modality expresses ability, volition, permission and obligation, while epistemic modality indicates "the speaker's confidence (or lack of confidence) in the truth of the proposition expressed" [1], or in other words, "epistemic modality speakers express their judgments about the factual status of the proposition" [2]. Both types of modality are frequently used in daily conversations, and epistemic modality is often used in academic writing too to indicate the researcher's epistemic judgment about the truth value of scientific data or research results. The present study will focus on the use of epistemic modality, which involves expressing both epistemic possibility and epistemic necessity. Although there have been quite some studies on modality both abroad and in China, research that focuses on the acquisition of English epistemic modality by Chinese learners is not adequate. $\mathrm{Hu}$ (2011) [3] did a study on the acquisition of English modality by Chinese EFL learners, in which both root and epistemic modal expressions were under investigation, but the epistemic modal verbs in the study included only "may" and "might" which express epistemic possibility. Other modal verbs which express epistemic possibility and modal verbs which express epistemic necessity were not in Hu's scope of investigation. In the present study, seven English modal verbs (including "can, could, may, might, will, would, and must" ) were put within the scope of investigation to see how they are chosen by Chinese EFL learners to express epistemic meanings that are correspondent to the Chinese modal verb “会” (hui) in different syntactic contexts, i.e., in negative, double negative or interrogative sentences. 


\subsection{Tolerance of Ambiguity}

Tolerance of ambiguity (TOA), or ambiguity tolerance, is a cognitive learning style. It was originally a psychological construct related to general learning, and later was used by Ely (2002) to explain individual cognitive differences specifically in language learning [4]. Ambiguity is interpreted as the uncertainty that learners feel when comprehending and using the new language [4]. Learners may feel unsure about the meaning of words/utterances during the course of listening/reading, or they may feel unsure about which is the correct form to use while speaking or writing in the new language. This mental state of feeling uncertain/unsure may inhibit learners from learning, depending on their degree of TOA. Wei (2020)'s study showed that ESL learners who have lower degree of TOA are less willing to communicate in the new language [5]. Hence, we can infer that higher degree of TOA is needed for learners to keep learning or using the new language.

Linguistic uncertainty is usually caused by interlingual differences between the learners' mother tongue and the target language, or by intralingual indeterminacy in the target language itself. The lack of determinacy is thought to be inherent especially in the productive skills of speaking and writing [4]. Indeterminacy and uncertainty are the key words to the understanding of ambiguity in second language acquisition (SLA). Although the study of TOA started more than half a century ago (when it was first proposed in 1962 as a psychological construct), generally speaking, research on it in the field of SLA has not been adequate in China $[6,7]$.

\subsection{Rationale for the Research Hypothesis}

The lack of determinacy was also mentioned by Coates (1983) when the feature of English modal verbs was described, and the understanding of indeterminacy is thought to be crucial to the understanding of modal verbs [1]. According to Coates (1983), indeterminacy of modal verbs includes "gradience, ambiguity and merger", among which ambiguity is understood to be characterized by having either this meaning or that meaning. Depending on the contexts, most modal verbs may sometimes have ambiguous meanings, which may make the L2 learners/users feel uncertain. Modal ambiguities do not only exist in the English modal system as revealed by Coates (1983) [1]. Similar ambiguities can be found in the modal systems of Chinese too. Lai (2020) made an analysis of both semantic and syntactic ambiguities inherent in the Chinese modal system [8].

Based on the description of TOA in Ely (2002) [4] and the study on the indeterminate feature of modal verbs in Coates (1983) [1], the present study has hypothesized that the acquisition of modal verbs may particularly need higher degree of TOA, as enormous ambiguities exist in the modal systems of both Chinese and English. Previous studies on TOA have investigated the relationship between TOA and language achievement in general, or between TOA and different kinds of learning strategies or language skills. But it seems there hasn't been any study on the relationship between TOA and modal acquisition in particular. Given the importance of epistemic modal use in academic writing to express judgments of doubt or conviction, this study intends to find out how well PhD students as potential researchers have mastered the use of English epistemic modals and whether their achievement in epistemic modal use is influenced by their degree of TOA. The tentative hypothesis is: participants who have lower degree of TOA might do less well in using the English epistemic modals. In other words, there might be a correlation between TOA and epistemic modal use. This is to be verified by a TOA survey and a modal test.

\section{Methods}

\subsection{Participants}

The participants in this study were $\mathrm{PhD}$ students in a university in China. They study for their PhD degree in different schools of the University, i.e., they specialize in different academic fields. They were required to take English lessons for one semester as a compulsory course, to improve their ability in academic English skills. They were mostly at the intermediate level in terms of English proficiency when they began the English course. In this course they were not given any training in the use of modal verbs as they were supposed to have learned about it in their previous years of study, because English has always been a compulsory course in both secondary schools and universities in China. These $\mathrm{PhD}$ students were asked to take a short modal test not long after the English course started, and a few weeks later they were asked to answer a TOA questionnaire. There were 3 classes of $\mathrm{PhD}$ students under investigation of this study, and 88 of them took the modal test. With test papers which were not fully completed being excluded, there remained 77 valid test papers. 91 of them participated in answering the TOA questionnaire, but to match their questionnaire sheets with their test papers, the questionnaire sheets of those whose test papers were not valid had to be excluded, and the questionnaire sheets of those who didn't take the modal test were also excluded, hence there remained 73 TOA questionnaire sheets for investigation. Among the 77 valid test papers, 4 of them belonged to students who took only the modal test and didn't participate in the TOA questionnaire survey, so these 4 test papers were also excluded. Therefore, what remained for analysis were 73 test papers and 73 TOA questionnaire sheets, which were paired up for a correlative study.

\subsection{Instruments}

A test on the use of modal verbs was designed, with modal sentences in pairs, one in Chinese and another one in English. Consisting of 32 pairs of modal sentences, this test examined the use of both root modals and epistemic modals, but only the use of English epistemic modals which are correspondent to the Chinese modal verb “会” was taken to be the focus of this study. This includes 8 pairs of epistemically modalized sentences that were interspersed among the 32 pairs of sentences on the test paper in order to make the focus of this study less transparent to the participants. For the English sentence in each of the 32 pairs of modal sentences, a blank in the sentence needs to be filled in with the appropriate form of 
one of the 7 modal verbs: can, could, may, might, will, would and must, according to the modal meaning expressed in the corresponding Chinese sentence. The 32 pairs of sentences were taken from different sources and the Chinese sentences in the 8 pairs of epistemically modalized sentences contain the modal verb “会” (hui) in its different forms according to syntactic contexts, for example, “不会” (bu hui) as the negative form, “不会不” (bu hui bu) or “不会没” (bu hui mei) as the double negative form, and “会不会” (hui bu hui) as the interrogative form. Actually modal verb “会” expresses both root modality and epistemic modality, but in this study only the sentences using “会” in the epistemic sense and the corresponding English sentences were chosen for investigation, aiming to see how Chinese $\mathrm{PhD}$ students express epistemic meanings conveyed by “会” (hui) with correspondent English modal forms.

The TOA questionnaire was taken from Ely (2002) [4]. It consists of 12 statements. The responses are in Likert scale format with four choices: Strongly Agree (SA), Agree (A), Disagree (D), and Strongly Disagree (SD). Different choice scores different points. This questionnaire as the scale for measuring the degree of TOA has been widely accepted by researchers on TOA. Validity and reliability of this questionnaire has been verified in the field of SLA [5, 7].

Charts made from Excel software are used to graphically show the types and rates of modal forms chosen by participants to fill in the blanks on the test paper. SPSS software (IBM SPSS 26.0) is used to detect whether there is correlation between the participants' scores in epistemic modal use and their scores of TOA.

\subsection{Scoring}

A correct modal form that is filled in each blank of the eight English epistemic sentences scores 6 points, therefore the highest possible score for epistemic modal use is 48 points, and the lowest possible score is 0 . The higher the score a participant gets, the better he/she is supposed to be at using English modal verbs.

For the TOA questionnaire, according to Ely (2002), choosing "Strongly Agree" scores 4 points, choosing "Agree" scores 3 points, choosing "Disagree" scores 2 points and choosing "Strongly Disagree" scores 1 point [4]. As there are 12 statements, the highest possible score is thus 48 points and the lowest score is 12 points. As "Strongly Agree" actually stands for intolerance of ambiguity, the higher the score that a participant gets on the questionnaire, the less tolerant of ambiguity he/she might be [7]. The scores of TOA will be further shown in the Results and Discussion section.

\section{Theoretical Basis}

The functionalist theories in SLA focus on not only "how linguistic knowledge is represented in the learners' mind", but also "how linguistic knowledge is used in discourse" [9]. On this production side, it is held that "syntax cannot be considered separately from semantics and pragmatics" [9]. As lack of determinacy can be especially perceived on the production side [4], the present study which uses grammatical exercises of filling in the blanks to elicit production data on modal use takes the functionalist theories as the most appropriate theoretical basis for interpreting the causes of modal errors made by the participants in this study.

\subsection{Klein's Theory About Matching and Embedding}

According to Klein (see [9]), language learners are faced with 4 tasks in terms of language processing: analyzing, synthesizing, matching and embedding, all of which are cognitive processes involved in language comprehension and production. In the present study, matching and embedding are the major tasks faced by participants when they filled in the blanks on the test paper. "Matching means the learner must continuously compare his current language variety with the target variety, and embedding means the learner has to make utterances fit the context (both situational and linguistic context) in which they occur" [9]. When learning a second language, learners are already acquainted with the form-function mappings in their mother tongue, their task is to match the forms in their mother tongue with the forms in the target language to fulfil the functions they want to express when they use the new language. When the matching between the mother tongue and the target language is wrong, the words they use in a sentence (i.e., the words they embed in syntactic contexts) may not be the right forms to express the intended functions. It is in this sense that Klein's theory is a functionally-driven one. In the present study, participants were required to fill in the blanks in the English sentences with the right choice of modal forms to express epistemic functions, which is actually an embedding exercise that involves matching during the choice-making process.

\subsection{MacWhinney's Competition Model About Form-Function Mapping}

The Competition Model is a performance model which examines the learners' behavior in language production. From the perspective of the present study, it can be interpreted in relation to the matching and embedding process in language production, during which competition between different forms may occur in the learners' mind. The idea of form-function mapping is essential to Competition Model: "any one form may realize a number of functions and any one function can be realized through a number of forms" [9]. Competition thus arises from "different devices or cues that signal a particular language function" [10].

\subsection{Theoretical Rationale of the Present Study}

According to previous studies on modal verbs, the multiple form-function mapping is especially true in terms of modal system, because any one modal verb/form may realize different functions (i.e., express different meanings, including root meanings and epistemic meanings), and any one function/meaning can be realized by different modal verbs/forms, which is true for both the Chinese modal system and the English one. There exists intralingual complexity 
within both of the modal systems in terms of form-function mapping. The form-function mappings of modal verbs between Chinese and English are even more complicated. Due to the semantic incongruity and syntactic complexity in each modal system, the process of matching modal forms between the two languages and the process of embedding the right form in the sentence may involve competition of different modal forms in the learners' mind. In the present study, competition of modal forms is expected to be something that can be partly observed from the way that participants fill in the blanks.

This paper will at first avail of the above theories to reveal the nature of modal errors made by participants. Then the relationship between epistemic modal use and TOA will be investigated by using IBM SPSS 26.0. The focus of this study is the use of English modal verbs to express epistemic meanings conveyed by the Chinese modal verb “会” (hui). The target of investigation is the matching of “会” with equivalent English modal forms when participants try to fulfil epistemic functions in the given sentences, to find out how ambiguity among modal verbs and competition between modal verbs might have led to errors in the matching and embedding process.

\section{Analysis of Epistemic Modal Errors}

The design of the modal test is based on "choice" (to investigate which modal form each participant chooses for the blank in each sentence and what might be the competing forms in the participants' mind during the choice-making process). The results of the modal test reveal that the participants made miscellaneous errors in their choices of English modal forms when they tried to express the epistemic functions in terms of possibility or necessity. Errors made by them have shown the influence of ambiguity on the use of modal verbs due to both interlingual and intralingual differences in the modal systems. The role of syntactic contexts in modal use has been made one factor to be examined through the modal test, as the modal meanings for participants to express in English are stated in the corresponding Chinese sentences by the negative form, the double negative form and the interrogative form of Chinese modal verb “会”. Fill-in-the-blank exercises designed in this modal test are meant to elicit production data on modal use, as ambiguity/uncertainty can be especially felt on the production side. In the following section, examples of answers given by the participants will be presented and analyzed. Examining them from the perspective of Error Analysis and functionalist theories, we can classify the errors they made into the following categories.

\subsection{Errors Caused by Interlingual Transfer}

Due to interlingual differences between the mother tongue and the target language, negative language transfer may bring about incorrect matching between the two languages in terms of both modality and negation in modal use.

\subsubsection{Errors Due to Incorrect Matching in Terms of Modality}

For the Chinese sentence “它会不会被风吹走了? ” and its equivalent English sentence “ it have been blown away by the wind?", as many as 25 of the participants chose "Would" to be embedded in the blank, which shows incorrect matching of the Chinese modal verb "会” (hui) to the English modal verb "Would". Although “会” in Chinese generally does express epistemic judgment related to events in the future and is quite often equivalent to "will/would" when expressing something that's going to happen, for example, "It will be blown away by the wind (它会被风吹走的)”. However, in the given sentence above (它会不会被风吹走了? ), “会不会” (hui bu hui) as the interrogative form of “会” is used to ask about epistemic possibility of something which happened in the past, and in this epistemic sense "will/would" is not the best choice to be embedded in the blank. The participants may have used "would" as the past tense of "will" to refer to possibility of the past event in the given sentence. This error is thus quite possibly caused by incorrect matching due to negative language transfer from the participants' mother tongue, with “会” very often being used to show future events. Actually “会” in Chinese has multiple meanings and can be matched with different English modal verbs according to syntactic contexts, and this kind of one-to-more correspondence between the two languages may have been a factor that causes ambiguity in the learners' mind. Not being sure of the form-function mapping in specific contexts, incorrect matching might occur and wrong modal form might be embedded in the given sentence.

Similarly, the interrogative “会” in the Chinese sentence “他会是搭错了公交车吗?” was also incorrectly matched to “Would” by 18 participants when they filled in the blank of the equivalent English sentence " he have taken the wrong bus?". The cause of embedding the wrong modal form in the blank may be the same one as explained above.

Besides, although all the modal verbs in English can be used to express epistemic judgments, the degree of confidence of the judgment expressed by each modal verb is different, ranging from low possibility to high possibility or necessity. This is not the case in terms of Chinese modal verbs. Although all Chinese modal verbs also express epistemic judgments, the difference between them is not in the degree of confidence, but in contextual constraints. The interrogative form of “会” is usually expressed by English modal verb "Could" or "Might", which shows epistemic possibility, not necessity. But the double negative form of “会” (for example, 不会不、不会没) means an epistemic judgment of the highest degree of confidence, i.e. epistemic necessity. And this needs to be expressed by the English modal verb "must". For example, in one of the Chinese sentences “她不会(还)没走”, double negative form “不会没” shows a judgment of epistemic necessity, which needs to be expressed by "must" in English ("She must have left"). But as shown in Figure 1, only 15 of the 73 participants chose "must" as the right English modal verb, some others chose "might", "may", "would", "could" and so on to express the meaning of “不会没”. These errors might have been caused by the difference between Chinese and English modals, showing that the participants wrongly matched the double negative form of Chinese modals which mean epistemic necessity to English modals which do not 
express judgments at the same degree of confidence, due to their insufficient understanding of the evidential weight expressed by English modals. It can be seen in Figure 1 that the modal forms participants chose to embed in the given sentence are miscellaneous, which reveals that there are enormous ambiguities among English modal verbs and the participants are not clear which is the right form to use or to embed in the particular syntactic context.

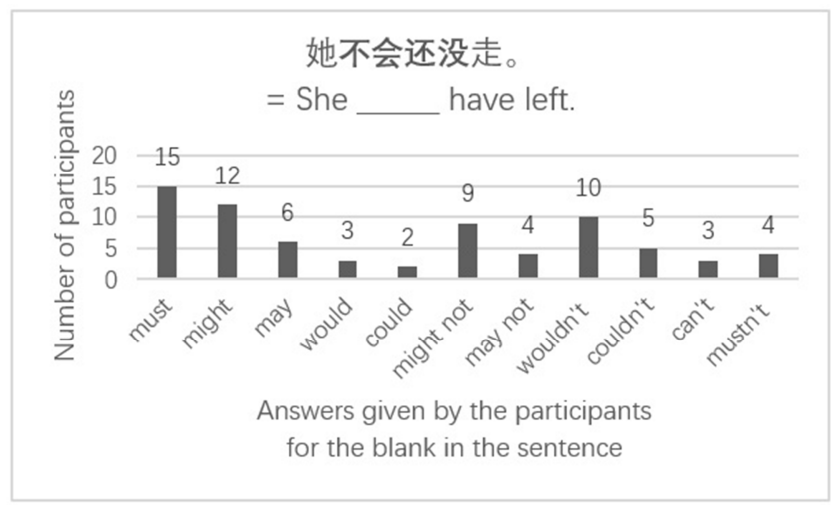

Figure 1. Double negative form of “会” (i.e., 不会没) and the English modal forms it is matched with by the participants (The correct answer to be filled in the blank should be "must").

\subsubsection{Errors Due to Interlingual Difference in the Use of Negation}

In Figure 1, for the Chinese sentence “她不会(还)没走” and its equivalent expression in English, apart from errors of incorrect matching due to inequivalent degree of epistemic confidence, there are quite some errors in terms of negation. The double negative form of a Chinese modal verb needs to be expressed by an affirmative English modal verb. But quite many participants matched the double negative form “不会没” with negative form of different English modals, such as "might not, may not, wouldn't, couldn't, can't, mustn't", as shown in Figure 1. It reveals influence from their mother tongue (Chinese), as “不会没” contains negative markers “不” (bu) and “没” (mei), which may have induced them to use the negative form of English modals. Similarly, for the Chinese sentence “他不会不知道，是知道了不说”, when participants matched double negative form “不会不” (bu hui bu) with English modal expressions, some of them also used negative form of English modals, such as "mustn't, couldn't, might not, wouldn't', possibly due to language transfer from Chinese in terms of the use of negative markers. It shows that the participants felt ambiguous about the use of negation when negative markers are not used in the same way in the two languages. According to Ely (2002), teachers need to make students understand that "one language cannot be directly mapped onto another" [4]. Due to interlingual differences, form-function mapping in terms of whether to use negative markers is also one thing that may produce ambiguity.

\subsection{Errors Caused by Intralingual Overgeneralization}

Overgeneralization means generalizing a rule in the target language or "creating a deviant structure on the basis of other structures in the target language" [9].

\subsubsection{Errors Due to Overgeneralization Related to Modality}

For the Chinese sentence “约翰现在不会在家” (“John can't be at home now”), the Chinese modal form “不会” (i.e., the negative form of “会”) needs to be expressed by “can't” in English, but only 13 of the 73 participants filled in the blank of the English sentence with "can't", 29 of them filled in the blank with "mustn't", and there are some other different choices made by them, as shown in Figure 2.

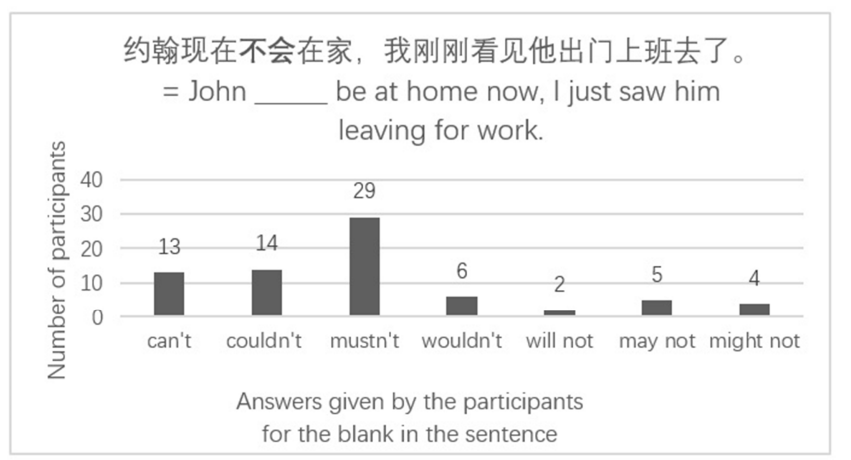

Figure 2. Negative form of “会” (i.e., 不会) and the English modal forms it is matched with by the participants (The correct answer to be filled in the blank should be "can't").

The negative form of “会” (i.e., 不会) in this Chinese sentence expresses epistemic confidence that something is definitely not possible. Participants who matched “不会” to "mustn't" may have overgeneralized the use of "must" in English which can mean epistemic confidence that something is $100 \%$ possible, and thus accordingly used its negative form to mean epistemic confidence that something is not possible. They didn't know that "epistemic MUST cannot be negated, and the gap in the paradigm is filled by can't" [1]. The incorrect matching of “不会” to “mustn't” is possibly caused by overgeneralization of the negation rule in terms of modality. It shows that the participants have had the knowledge that "must" in English means the highest epistemic confidence and on the basis of this knowledge they have generalized it to the linguistic context of negative sentences. They were not fully aware that although "must" can express epistemic meaning, its negative form can only express root meaning. Unawareness of a certain modal verb's semantic difference in different syntactic contexts is the possible cause of overgeneralization in its use.

Another typical error is that participants tend to overuse "might/may" to show epistemic possibility. For example, in the

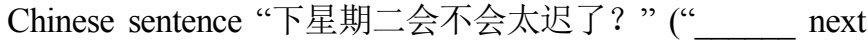
Tuesday be too late?"), 14 participants matched “会不会” to "Might", and 13 participants matched “会不会” to "May", neither of which is correct matching; In another Chinese sentence “会不会落空?” (“___ it come to nothing?”) as shown in Figure 3, 13 participants matched “会不会” to "Might”, and 12 participants matched “会不会” to "May". Although in English "might/may" is often used to show epistemic possibility, in the equivalent English expression of the above two examples shown in this paragraph, "Might/ May" is not the correct choice, as "Would" and "Will" are needed respectively for the above two 
blanks in the English sentences. According to Celle (2005), English "will", apart from referring to time, can express conjecture (which is a kind of epistemic judgment) [11]. Giannakidou \& Mari (2018) also acknowledged an interaction between modality and tense [12]. "The relationship between futurity and modality is often asserted in the context of the 'future tense' modals, such as will' [1]. As the above two examples are related to futurity, "will/would" is a better choice over "might/may" as an epistemic modal. The errors made by participants in the above two examples show that "might/may" has been overgeneralized and overused by some of the participants to mean epistemic possibility.
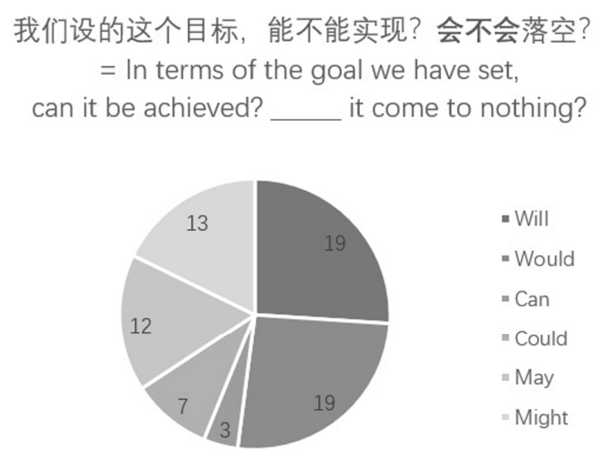

Figure 3. Interrogative form of “会” (i.e., “会不会”) and the English modal forms it is matched with by the participants (The correct answer to be filled in the blank should be "Will").

For the interrogative “会” in the Chinese sentence “他会是 搭错了公交车吗?” (“会” he have taken the wrong bus?"), 15 of the participants filled in the blank with "May", which they may have taken to express epistemic possibility just like "Might", but they didn't realize that when "may" expresses epistemic meaning it can only be used in affirmative sentences, not in interrogative sentences. Insufficient understanding of the syntactic contexts for the use of "may/might" may thus have caused incorrect matching and embedding. This shows syntactic contexts do play a role in determining which is the best form to be used/embedded, but the participants may not have had sufficient knowledge of form-function mapping under the constraint of contexts. Erroneous overgeneralization of "may/might" have thus shown that unawareness of semantic difference and syntactic differentiation is indeed a factor that may cause intralingual ambiguity in participants' perception of modal verbs.

\subsubsection{Errors Due to Overgeneralization Related to Tense}

Errors of tense can be quite often seen on the test papers of the participants. For each Chinese modal verb, there are no tense variations. But for most English modals, there are both the present tense form and the past tense form, such as may/might, can/could, will/would etc. The awareness of tense variations of the English modal verbs caused quite many errors, as students may overgeneralize the rule of tense in the target language. For example, in the Chinese sentence “约翰 现在不会在家”, the modal phrase “不会”, which is the negative form of “会”, should be expressed by the English modal "can't" to mean something isn't possible at the moment of speaking, but only 13 of the participants got it right, while 14 of the participants used the past tense form "couldn't" instead of the present tense form "can't", as shown in Figure 2. In the sentence “会不会落空?”, the modal phrase “会不会” needs to be expressed by "Will" to mean possibility in the future, but only 19 of the participants chose to use "Will", and another 19 of them chose the past tense form "Would", as shown in Figure 3. It can be seen that quite a number of participants made mistakes due to overgeneralization of the use of tense in the target language which may have made them choose to use variations of tense.

\subsection{Perception of Ambiguity by the Participants in Terms of Modal Use}

Ambiguity in second language learning means linguistic uncertainty felt by the language learners, as they may feel unsure about forms and rules in the target language, possibly due to intralingual and interlingual complexity in terms of form-function mapping. The final item on the test paper designed for the present study was for participants to voluntarily comment on their feelings of doing the modal test. From the comments that some of them wrote down, the existence of ambiguity that they felt while taking the modal test can indeed be noticed.

For example, one of them commented: "It's so difficult! I am confused by words like can, could, may, might, will, would, must and so on". Another one of them wrote: "Could and Can is easy to be confused (except when there are explicit tense markers in the sentence)". Someone wrote: "Would and Could is confusing". Another participant wrote: "I can't differentiate these modal verbs; I feel unable to tell which is the right one to be filled in the blank". Confusion mentioned in the above comments is clearly related to the concept of ambiguity, which made them feel uncertain about the semantic distinctions between different modal verbs and unsure about which is the right modal form to be embedded in the given sentence.

Palmer (1979) pointed out that "the overall picture of the modals is extremely messy and untidy" (See [1]). Coates (1983) also claimed that the meanings of both root modal verbs and epistemic modal verbs are fuzzy [1]. The words "messy, untidy, and fuzzy" used by them clearly indicate the ambiguousness of English modal verbs in terms of form-meaning mapping. This is also shown in the written comments of some participants. Someone of them wrote: "I felt I'm made dizzy by these modal verbs", and this comment is followed by an emoticon which shows confusion and bewilderment. It reveals that this participant may have a low degree of tolerance of ambiguity. Another participant wrote "I may have overused can/could and may/might. I don't feel good about what I did". The lack of confidence in what he/she did shows the negative effect of ambiguity on his/her performance. The above comments made by the participants clearly indicated that linguistic ambiguity can make learners "experience discomfort" [4].

But for participants of higher tolerance of ambiguity, they may try to discover rules among the confusion or to disentangle 
the confusing threads of information in the situation. For example, one of them wrote: "I felt there are great differences between Chinese and English modals" but he/she didn't seem to be bothered by the feeling of differences; Another one wrote: "I discovered that the same meaning can be expressed by different modal verbs when in different contexts." This shows he/she has discovered the one-to-more correspondence in terms of form-function mapping. As Ely (2002) pointed out, what teachers need to do is to help students understand "uncertainty is really an opportunity to discover something new about the L2" [4]. According to the Competition Model, "the learner's task is to discover the particular form-function mappings that characterize the target language" [9].

\subsection{Competition of Different Modal Forms in the Participants' Mind}

When participants fill in each blank, they may be faced with more than one modal form competing in their mind, unless they are completely sure which is the correct form to be embedded in the sentence. Given the ambiguity felt by some of them in terms of modal use, competition does arise when they judge the fitness of a modal form in a certain context. The competing process in their mind actually involves form-function matching. The answer they eventually embed in each blank is actually the result of competition. On neat answer sheets handed in by some participants the specific form-function mapping and competing process which took place in their mind cannot be seen. But when a participant wrote a modal verb in the blank and then crossed it out and filled in another modal verb instead, it clearly shows the competition between these two modal verbs in the participant's mind. The following are some examples from the participants' test papers.

For the sentence "John be at home now”(“约翰现 在不会在家”), there were two participants who at first filled in the blank with "mustn't" and then replaced it with "can't", and a third participant who previously filled in the blank with "can't" and later replaced it with "mustn't". In this example, "can't" is the right modal form for the blank to mean highest epistemic confidence that something is not possible, and "mustn't" is not the right choice. From this example it can be seen that there is ambiguity between "mustn't" and "can' $t$ " in the participants' mind and these two modal verbs compete with each other when participants try to embed the right one in the sentence. The wrong form "mustn't" has sometimes got competitive strength for this blank because participants have learned that "must" in English can be used to show epistemic confidence that something is definitely possible, so they infer that the negative form of "must" is needed in this blank to show epistemic confidence that something is not possible. The wrong inference leads to the error of using "mustn't" for this blank, as the negative form of "must" (i.e., "mustn't") can't be used to express epistemic meaning. Due to competition in the form-function mapping process, some participants eventually made the right choice but some of them might have at first chosen the right modal verb but later replaced it with a wrong one. The competition between "mustn't" and "can't" in this example is somewhat brought about by intralingual overgeneralization of the epistemic use of "must".

For the sentence “She__ have left” (“她不会还没走”), competition can be clearly seen in terms of whether to use negation and which modal verb to be used. For example, one of the participants at first wrote down "might" and then replaced it with "wouldn't", one of them replaced "would" with "can't", one of them replaced "must" with "may not", and another one of them previously filled in the blank with "won't", then crossed it out and wrote "wouldn't" instead, and then crossed it out again and filled in the blank with "may not". These variations in their answers show that there were enormous ambiguities between these modal forms and participants felt quite unsure which modal verb needs to be used and what is the right form of them in terms of tense and negation. Competition between these modal forms arises in the process of matching and embedding due to interlingual interference from the L1. According to Ellis (1999), the Competition Model has "provided a convincing account of a number of aspects of L2 acquisition which any theory must consider, including the role of the L1" [9].

For the sentence “__ he have taken the wrong bus?” (“他 会不会是搭错车了?”), confusion and competition between different modal verbs can also be clearly seen. A participant at first wrote "could" and then replaced it with "will", another participant replaced his first choice "would" with "may" and then crossed out "may" and replaced it with "would" again, and still another participant at first wrote down "might" in the blank, then replaced it with "may", and later crossed out "may" and replaced it with "would". This kind of language behavior in test-taking reveals real-time processing of the competitive strength of different modal verbs. The process of competition shows that the participants are not sure of the proper weights that are assigned to different modal verbs "in terms of the probability of their use in signaling a given function" [9].

Whether a modal form wins or loses in the competition is determined by their weights or "conflict validity" [9]. Ambiguity about the conflict validity of each modal verb leads to possible misuse of them. As indicated in the above analysis of modal errors, the misuse of modal verbs is possibly caused by interlingual interference or intralingual overgeneralization, which may result in wrong form-function mapping during the embedding process. The increase of modal input in language teaching may be needed to help L2 learners adjust the weights of different modal verbs and improve their perception of form-function mapping [13]. With more modal input and more practice, learners may have a better grasp of the competitive weights of different modal verbs and may experience less ambiguity in terms of modal use.

\section{Results and Discussion About the Correlation}

\subsection{Participants'Degree of TOA and Their Use of Epistemic Modals}

According to the measurement scale of TOA in Ely (2002) [4], the range of TOA scores is from 12 to 48 which indicates a 
continuum from high tolerance of ambiguity to intolerance of ambiguity, i.e., the higher a participant's score on the TOA questionnaire, the lower his/her degree of TOA, as shown in Figure 4.

\section{SCORING}
1. Count each of your scores in this way: $S A=4 \quad A=3 \quad D=2 \quad S D=1$
2. Total your score for all statements and compare with the following scale.

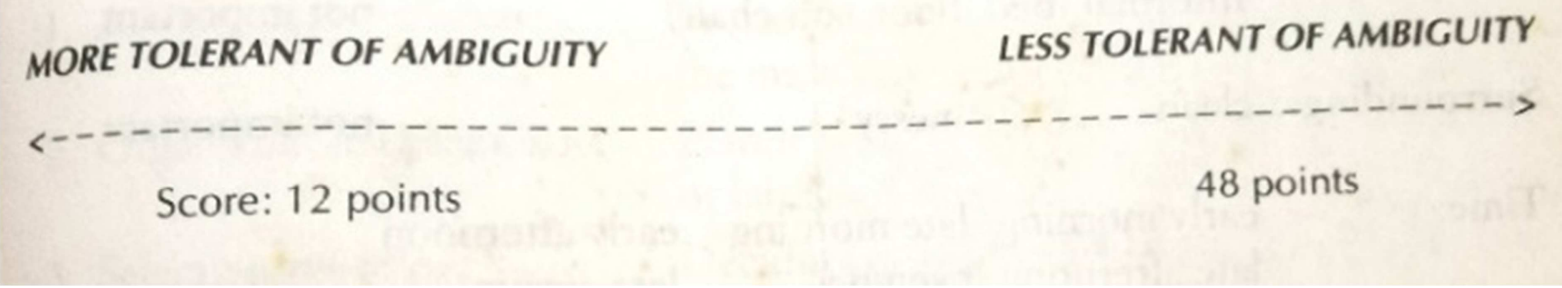

Figure 4. Scoring of TOA (taken from Ely, 2002).

As 30 is the medium number in the range (from 12 to 48), scores between 12 and 29 is taken by this study to mean higher tolerance of ambiguity (e.g., 12 means the highest degree of tolerance), and scores between 31 and 48 is to mean lower tolerance of ambiguity (e.g., 48 indicates the lowest degree of tolerance). The results of the questionnaire survey show that the highest TOA score among the participants is 40 , and the lowest is 20 , with the mean of TOA scores being 30.7945 , as shown in Table 1. As none of the participants got a TOA score lower than 20 , it means none of them had very high tolerance of ambiguity. From the figures in Table 2 which displays the distribution of the TOA scores in this survey, it can be seen that the general degree of TOA among the participants is not high, with 40 of them (i.e., more than half of them) having low degree of TOA and only 24 of them in the range of higher tolerance of ambiguity. This means quite many of the participants are less tolerant of ambiguity, therefore they might not be able to tolerate the feeling of uncertainty caused by interlingual and intralingual differences.

Table 1. Paired samples statistics about the scores of TOA and the scores of the modal test.

\begin{tabular}{llll}
\hline & Mean & Number of participants & Standard Deviation \\
\hline Scores of TOA & 30.7945 & 73 & 4.24251 \\
Scores of EMU & 16.9726 & 73 & 8.27978 \\
\hline
\end{tabular}

Note: EMU stands for epistemic modal use.

Table 2. Descriptive statistics about the distribution of TOA scores among the participants.

\begin{tabular}{llll}
\hline & More tolerant & Medium & Less tolerant \\
\hline Scores of TOA & $20-29$ & 30 & $31-40$ \\
Number of participants & 24 & 9 & 40 \\
\hline
\end{tabular}

The scores of epistemic modal use range from 0 to 48 , and the higher the score means the better the achievement in modal use. In the present study, the highest score among the participants is 39 , and the lowest is 0 . The mean of epistemic modal use is 16.9726 , as shown in Table 1. Altogether 34 of the participants scored below the mean (16.9726), which indicates a general picture of low achievement in epistemic modal use. The mean (as low as 16.9726) shows that most of the participants have not mastered the usage of English epistemic modals very well. And according to Table 2, most of them are not tolerant of ambiguities either, hence the question is raised: Is there any correlation between TOA and epistemic modal use? The answer to this question will be shown below.

\subsection{Correlation Between TOA and Epistemic Modal Use}

The correlation coefficient between the scores of TOA and the scores of epistemic modal use was calculated by IBM SPSS 26.0. The results are shown in the following figures taken from the SPSS reports. 


\begin{tabular}{llr|r} 
& & \multicolumn{1}{c}{$\begin{array}{c}\text { Scores of } \\
\text { Tolerance of } \\
\text { Ambiguity }\end{array}$} & $\begin{array}{r}\text { Scores of } \\
\text { Epistemic } \\
\text { Modal Use }\end{array}$ \\
\hline $\begin{array}{l}\text { Scores of Tolerance of } \\
\text { Ambiguity }\end{array}$ & Pearson Correlation & 1 & $-.262^{\star}$ \\
\cline { 2 - 4 } & Sig. (1-tailed) & 73 & .012 \\
\hline $\begin{array}{l}\text { Scores of Epistemic } \\
\text { Modal Use }\end{array}$ & Pearson Correlation & $-.262^{\star}$ & 73 \\
\cline { 2 - 4 } & Sig. (1-tailed) & .012 & 1 \\
\hline & $\mathrm{N}$ & 73 & 73 \\
\hline
\end{tabular}

*. Correlation is significant at the 0.05 level (1-tailed).

Figure 5. Pearson correlation coefficient at the 0.05 level (1-tailed).

\begin{tabular}{llr|r} 
& & \multicolumn{1}{|c}{$\begin{array}{c}\text { Scores of } \\
\text { Tolerance of } \\
\text { Ambiguity }\end{array}$} & $\begin{array}{r}\text { Scores of } \\
\text { Epistemic } \\
\text { Modal Use }\end{array}$ \\
\hline $\begin{array}{l}\text { Scores of Tolerance of } \\
\text { Ambiguity }\end{array}$ & Pearson Correlation & 1 & $-.262^{\star}$ \\
\cline { 2 - 4 } & Sig. (2-tailed) & 73 & .025 \\
\hline N & Pearson Correlation & $-.262^{\star}$ & 73 \\
\hline $\begin{array}{l}\text { Scores of Epistemic } \\
\text { Modal Use }\end{array}$ & Sig. (2-tailed) & .025 & 1 \\
\cline { 2 - 4 } & $\mathrm{N}$ & 73 & 73 \\
\hline
\end{tabular}

${ }^{\star}$. Correlation is significant at the 0.05 level (2-tailed).

Figure 6. Pearson correlation coefficient at the 0.05 level (2-tailed).

From Figures 5 and 6, it can be seen that correlation is significant at the 0,05 level (both 1-tailed and 2-tailed), which means there is 95 percent of confidence to say that there is correlation between the two variables.

\section{Paired Samples Correlations}

\begin{tabular}{l|r|r|r} 
& $\mathrm{N}$ & Correlation & \multicolumn{1}{c}{ Sig. } \\
\hline $\begin{array}{l}\text { Scores of Tolerance of } \\
\text { Ambiguity \& Scores of }\end{array}$ & 73 & -.262 & .025 \\
Epistemic Modal Use & & & \\
\hline
\end{tabular}

Figure 7. The correlation coefficient between TOA and epistemic modal use.

From Figures 5, 6 and 7, it can be seen that the correlation coefficient is -.262 , with "-." as a negative symbol, which means it is a negative correlation. That is, the higher the score of TOA, the lower the score in epistemic modal use. As was pointed out above, for the measurement scale of TOA, the higher the score on the questionnaire means the lower the degree of TOA, i.e., the higher the score of TOA a participant gets, the less tolerant of ambiguity he/she is. Therefore, the correlation results shown in the above figures actually indicate that the less tolerant of ambiguity a participant is, the lower score he/she gets in terms of epistemic modal use. In other words, the correlation between the scores of TOA and the scores of epistemic modal use is a negative one, while the correlation between the degrees of TOA and the scores of epistemic modal use is a positive one, which means the lower the degree of tolerant of ambiguity, the lower the score in epistemic modal use.

\subsection{Implications}

The results of this correlative study have verified the relationship between TOA and language achievement, and the debilitating effects of TOA on language learning can be seen. What some of the previous studies showed was the correlation 
between TOA and general achievement in second language learning. The present study has shown the correlation between TOA and a particular aspect of language learning: the acquisition of English modals, especially epistemic modals. Based on the importance of epistemic modality in academic language [14, 15], the results of the present study imply that it is quite necessary to enhance PhD students' acquisition of epistemic modals for the purpose of improving their academic language skills, and one way to do that is to raise their degree of TOA. As was pointed out in Ely (2002), intolerance can be a problem, and teachers need to raise students' consciousness about the importance of TOA and help them to "make changes in their feelings about uncertainty" [4]. What's proven in the present study is that higher tolerance of modal uncertainty is needed for better achievement in epidemic modal use. As very high tolerance of ambiguity can also lead to language learning problems [4], the present study suggests that students be given pedagogical help to move from intolerance of ambiguity to higher tolerance but not the highest. What is the most appropriate degree of TOA in modal acquisition is worthy of more exploration by researchers.

\section{Conclusion}

The major findings of this study are summed up as follows: (1) There is significant correlation between epistemic modal use and Tolerance of Ambiguity: the less tolerant of ambiguity the students are, the lower their score will be in the use of epistemic modals, which means raising students' degree of tolerance of ambiguity is important in academic-oriented modal acquisition; (2) Non-English-major PhD students who participated in this study haven't got very good command of epistemic modals to express conviction or doubt in English statements, and the errors they made in epistemic modal use can be traced to interlingual transfer or intralingual overgeneralization. It is shown in the present study that even at the stage of PhD study, students still need explicit training in modal use, especially epistemic modal use. Otherwise, their limited capability in using epistemic modals may make their academic writings marked by unwarranted epistemic judgments.

Limitations of this study need to be noted: it is not based on a big sample, thus the data in this study is only descriptive, not inferential. The generalizability of the results in this study needs further verification.

This study investigated Chinese speakers' use of English modals in relation to their degree of TOA. It is recommended that future studies investigate how speakers of English use Chinese modals when they learn Chinese and whether it is influenced by TOA. As the Chinese modal system is characterized by even more ambiguities and fuzziness, a correlation between TOA and acquisition of Chinese modals might also be detected. Think-aloud protocol is recommended to be used in future studies to seek more evidence for the ambiguity that participants may perceive during the matching and embedding process when several modal forms compete in their mind. The modal system is a complex system which is far from being orderly and simple [2]. This is especially true for modal systems across different languages. Hence, the competition of different modal forms in the participants' mind during the process of form-function mapping between different languages is worthy of more investigation.

\section{Acknowledgements}

This paper is the research results from the Humanities and Social Sciences Project (15YJA740017) which is funded by Ministry of Education of China. I'm grateful for its financial support on the study of modal acquisition and Tolerance of Ambiguity.

\section{References}

[1] Coates, J. (1983). The semantics of the modal auxiliaries. London: Croom Helm: 10-13; 18; 233; 238.

[2] Palmer, F. R. (2007). Mood and modality ( $2^{\text {nd }}$ edition). Beijing: World Publisher Corporation: 8; 14.

[3] Hu, C. Y. (2011). Constructing the interlanguage modal system: L2 acquisition of modality by Chinese EFL learners. Beijing: Science Press: 89; 121; 132.

[4] Ely, C. (2002). Tolerance of ambiguity and the teaching of ESL In "Learning styles in the ESL/EFL classroom" (edited by Joy M. Reid). Beijing: Foreign Language Teaching and Research Press: 87-93; 217.

[5] Wei, X. B. (2020) A structural analysis of college students' L2 motivational selves, intolerance of ambiguity and willingness to communicate. Foreign Languages and Their Teaching, 1: 71-80.

[6] Xu, X. J. (2017). Literature review of research on ambiguity tolerance in Second Language Acquisition in China in the past 20 years. Journal of Chengdu Normal University, 33 (10): $72-77$.

[7] Zhang, S. M. (2012). A multi-perspective review of Tolerance of Ambiguity studies in the past 50 years. Foreign Language World, 2: 89-95.

[8] Lai, P. (2020). Semantic and syntactic ambiguities in the acquisition of Chinese modal verbs: based on intralingual and interlingual differences. Linguistics and Literature Studies, 8 (4): 206-214.

[9] Ellis. R. (1999). The study of Second Language Acquisition. Shanghai: Shanghai Foreign Language Teaching Press: 59; 369-370; 374; 378 .

[10] Ellis, R. (2015). Understanding Second Language Acquisition ( $2^{\text {nd }}$ edition). Oxford: Oxford University Press: 213.

[11] Celle, A. (2005). The French future tense and English will as markers of epistemic modality. Languages in Contras, 5 (2): $181-218$.

[12] Giannakidou, A. \& Mari, A. (2018). A unified analysis of the future as epistemic modality. Natural Language and Linguistic Theory, 36 (1): 85-129.

[13] Lai, P. (2016). A multiple-perspective study on English speaker's acquisition of Chinese modal verbs. Sun Yat-sen University Press: 35 . 
[14] Song, L. Y. (2008). On the role of epistemic modality in academic spoken language. Master Thesis of Heilongjiang University, China: Page II.
[15] Vold, E. T. (2006). Epistemic modality markers in research articles: A cross-linguistic and cross-disciplinary study. International Journal of Applied Linguistics, 16 (1): 61-87. 